\title{
Severe Acute Respiratory Syndrome Coronavirus-2 (SARS-CoV-2): Epidemiology and Vaccinology in Nigeria
}

\author{
Ridwan Olamilekan Adesola ${ }^{1 *}{ }^{\star}$, Oluwatobi Emmanuel Oladele $^{2}{ }^{\circledR}$, Ahmed Oluwasegun Tajudeen $^{3}{ }^{\circledR}$, \\ Ogundepo Oluwatobi Moses $^{2}{ }^{\circledR}$, Murali Dinesh ${ }^{4}{ }^{\circledR}$
}

${ }^{1}$ Department of Veterinary Medicine, Faculty of Veterinary Medicine, University of Ibadan, Ibadan, Oyo State, Nigeria

${ }^{2}$ Department of Microbiology, University of Lagos, Akoka, Lagos State, Nigeria

${ }^{3}$ Department of Microbiology, Olabisi Onabanjo University, Nigeria

${ }^{4}$ Division of Pathology, ICAR-Indian Veterinary Research Institute, Bareilly, U.P, India

Corresponding Author: Ridwan Olamilekan Adesola, MD, Department of Veterinary Medicine, Faculty of Veterinary Medicine, University of Ibadan, Ibadan, Oyo State, Nigeria. Tel: +234-8105217902, Email: radesola758@stu.ui.edu.ng

Received March 20, 2021; Accepted April 27, 2021; Online Published May 3, 2021

\begin{abstract}
Coronavirus disease 2019 (COVID-19), confirmed as the global pandemic on March 11, 2020, by the World Health Organization (WHO), was caused by the outbreak of an emergent severe acute respiratory syndrome coronavirus 2 (SARS-CoV-2), which was first reported in Wuhan city, China, in December 2019. Based on the previous pandemic, such as severe acute respiratory syndrome (SARS) from 2002 to 2003, Middle East respiratory syndrome coronavirus (MERS-CoV) in 2012. The scientific developments have fast-tracked our insights SARS-CoV-2 epidemiology, likewise vaccinology relevant for developing drugs for viral infections treatment. As there are not many detailed interventions and vaccines available for disease control, the pandemic COVID-19 poses countless threats to global public health, causing a great level of insecurity and unrest worldwide. To provide an inclusive overview to global health authorities and prospective readers worldwide, we detailed in this review the epidemiology and vaccinology of SARS-CoV-2 in Nigeria.

Keywords: COVID-19, SARS-CoV-2, MERS, Epidemiology, Vaccinology
\end{abstract}

Citation: Adesola RO, Oladele OE, Tajudeen AO, Moses OO, Dinesh M. Severe acute respiratory syndrome Coronavirus-2 (SARS-CoV-2): epidemiology and vaccinology in Nigeria. Int J Travel Med Glob Health. 2021;9(2):60-69. doi:10.34172/ijtmgh.2021.10.

\section{Introduction}

In the 1960s, human coronaviruses were discovered and found responsible for most respiratory or gastrointestinal diseases in the human population. Coronavirus's class was named after the virions with a characteristic "crown-like" morphology when viewed under electron microscopy. ${ }^{1}$ These viruses chiefly affect the epithelial cells of the gastrointestinal and respiratory tracts and cause several respiratory diseases and acute respiratory distress syndrome, pneumonia, and sepsis. ${ }^{2}$ Coronavirus family has two strains: the severe acute respiratory syndrome coronavirus 2 (SARS-CoV-2) and the Middle East respiratory syndrome coronavirus (MERS-CoV) for earlier outbreaks. In 2002 and 2003, SARS-CoV caused a global outbreak that began in Guangdong province, China. The disease affected over 8000 people and caused severe pulmonary diseases in several countries. ${ }^{3}$ Also, Saudi Arabia recorded the first outbreak of MERS-CoV in 2012 and was responsible for severe respiratory illnesses in various countries in the Middle East. ${ }^{4}$

There was an outbreak of a new strain of Coronavirus disease in December 2019, which caused severe acute respiratory syndrome (SARS) of unidentified etiology reported from China. Most of the cases reported were connected to a seafood market (wet market) in Wuhan, Hubei province, China. ${ }^{5}$ This outbreak appeared to be a zoonotic transmission from horseshoe bats (Rhinolophus malayanus) to man. However, this has not been fully proven because of the scarcity of scientific data on sequencing SARS-CoV genomes. ${ }^{6}$ As this outbreak continued, it was obvious that the virus can undergo human-to-human transmission through close contact, especially infections among health care workers. ${ }^{7}$

In Wuhan, severe cases of pneumonia were prevalent, which could be led to SARS-CoV-2 infection. After a full phylogenic analysis and genome sequencing of SARS-CoV-2, it was

Copyright $\odot 2021$ The Author(s). This is an open-access article distributed under the terms of the Creative Commons Attribution License (http:// creativecommons.org/licenses/by/4.0), which permits unrestricted use, distribution, and reproduction in any medium, provided the original work is properly cited. 
confirmed that this virus is a beta-coronavirus in a similar subgenus as SARS viruses dissimilar array. It was related to a bat Coronavirus, thus proposing that the principal source may be from bats. ${ }^{8,9}$ This infection was observed to spread quite quickly to numerous other countries. On January 30, 2020, WHO declared COVID-19 as a Public Health Emergency of International Concern (PHEIC), ${ }^{10}$ and 11th February 2020 declared COVID-19 the new Coronavirus disease. ${ }^{11}$ after that, it was formally confirmed on March 11, 2020, like a pandemic. Person-to-person transmission of SARS-CoV-2 pathogens was observed via respiratory droplets or close contact with a person infected with SARS$\mathrm{CoV}-2$, discharges from the nose, or saliva from a diseased person. Indirect transmission has also been observed to occur through fomites due to touching contaminated surfaces or objects in the immediate environment around an infected person. ${ }^{12}$ The viral transmission is relatively efficient, and as a result, the virus spreads rapidly from person to person. Evidence has also been proven that the virus can be contacted by people who do not show symptoms of COVID-19 or have a mild infection. ${ }^{12}$ The incubation period of COVID-19 ranges from 2 to 14 days but averages about seven days, ${ }^{11-14}$ and the average reproductive number $\left(\mathrm{R}_{0}\right)$ for Nigeria is estimated to be about $2.63 .^{15}$

While most young infected people with the coronavirus- 19 . They were observed to experience slight to moderate respiratory infection and recover without requiring any extraordinary intervention. Some young adults do not recover that easily. ${ }^{16}$ Patients with COVID-19 experienced indications such as dry cough, dyspnea, fever, and bilateral infiltrates on chest imaging. ${ }^{17}$ Other less severe symptoms include aches, pains, sore throat, diarrhea, conjunctivitis, headache, the recent loss of smell or taste, staining of fingers or toes, and a skin rash. ${ }^{18}$

The COVID-19 virus infects all age groups of people. However, the infection in children has been observed to be less severe and less common than in adults. ${ }^{18}$ About $1 \%-5 \%$ of children were tested positive with the COVID-19 virus in a systematic review report. These children were mostly reported to have the mild respiratory syndrome and hardly died from the disease. ${ }^{19}$ However, the risk of severe infection is higher in those with underlying health conditions such as diabetes mellitus, cardiovascular diseases (CVD), cancers, and chronic respiratory diseases, and older people. ${ }^{20}$

Some factors such as temperature, humidity, and altitude may be linked with the transmission of the virus. ${ }^{21}$ Emergent evidence proposes that dry and cold conditions increase transmission while humid and warm conditions may reduce infection rates. ${ }^{22-24}$ In some countries, a high latitude has been related to higher rates of cases and deaths. ${ }^{25}$ However, there is a need for further studies to confirm the cogency of these discoveries.

\section{Epidemiology}

The distribution of diseases is defined in terms of person, time, and place, or who, when, and where. COVID-19's first case was identified in Nigeria on February 27, 2020, in a visiting
Italian. ${ }^{26} \mathrm{~A}$ total of 119855035 cases of COVID-19 infection were confirmed worldwide by March 13, 2021, with 2,655,185 deaths reported according to the WHO. Furthermore, over 219 territories and countries have been reported with at least a case of infection of COVID-19. The ten countries with the highest load of the infection include the United States of America recorded with 30002491 cases, Brazil with 11368316 , India with 11358643 , Russia with $4,380,525$, the United Kingdom with 4253820 , France with 4015560 , Italy with 3,201,838, Spain with 3183704, Turkey with 2866012 and Germany with 2563092 . All the continents in the world have reported at least a case. Africa has the least number of COVID-19 cases while the European region has the maximum number of cases reported. ${ }^{26}$ On February 24, 2020, the first confirmed COVID-19 case in Africa was brought from Europe into Egypt. Since then, there has a sturdy rise in the number of infections in Africa, the high capacity of business and tourism between Europe and Africa. ${ }^{27}$

Ever since then, the numbers of the disease confirmed cases have been on the increase, with a total of 163837 as of April 12, 2021. ${ }^{28}$ According to the Africa Centers for Disease Control and Prevention (CDC), on April 6, 2021, at 9 AM East African time, a total of 4280598 COVID-19 infection cases had been reported with 114083 deaths. The majority of the cases were found in North Africa (Sudan) with 27 823, followed by West Africa with 261116 cases. However, the least number of reported cases with 102734 was found in the Central Africa region. The most affected countries in the WHO African Region include Senegal (1329), South Africa (7572), Nigeria (2950), Algeria (4838), Ghana (2718), Cameroon (2265), Cote d'Ivoire (1464), and Guinea (1811). These countries make up about $40 \%$ of the reported cases in the African region..$^{22,29}$ Although there is the argument that the lack of testing in large numbers because of low testing facilities could be one reason for reduced cases of reduced cases COVID-19 in Africa. It does not rule out the possibility of the influence of climate on SARS CoV-2 spread.

The epidemiology of COVID-19 cases in Nigeria would be described majorly in this study about the place, person, and time.

\section{The Person}

Although the data for COVID-19 cases are fast-changing, the infection affects all ages, both young and older people, and correspondingly affects both the immunocompromised and healthy people. People between the ages of 25 and above are the most affected adult patients, while few cases occur between children and infants. ${ }^{30}$ When a study was done on the early transmission dynamics of the novel Coronavirus, it was reported that the majority of affected patients were males. ${ }^{30}$ Also, most of the confirmed cases in Nigeria are between 20-59 years, with most males compared to females (Figure 1). This major diversity between males and females can be related to the stronger immune system in females than males, leading to the high prevalence of underlying diseases like high blood pressure and liver diseases in men that contribute to COVID-19 negatively. 
Similarly, an enzyme like angiotensin-converting enzyme 2 (ACE2) contributes essentially too high susceptibility of man to CVOID-19 infection than female. Researchers reported that man has a high amount of ACE2 in blood than females, and ACE2 enables the spread of SARS CoV-2 in the human cell. ${ }^{30,31}$ Moreover, the overall case fatality rate hitherto is not much. These data of the Nigeria CDC have been aggregated by age and sex.

A more significant portion of the people infected with COVID-19 in Europe and China were identified in the older group of individuals and those with underlying disease conditions, including diabetes, hypertension, simultaneous CVD (as well as cardiac arrest and coronary heart disease), myocardial injury, and obesity. ${ }^{32-34}$ This is due to a low level of antibodies in these older groups and patients with underlying conditions to protect them from this infectious agent.

\section{The Place}

The first COVID-19 case was recorded on February 25, 2020, from an Italian visitor on a business trip to the Ewekoro cement plant in Ogun State, southwest Nigeria. ${ }^{35}$ Since then, the spread of this disease has been recorded to cover several states in Nigeria. Currently, all the 36 states of the federation of Nigeria have at least one confirmed case of the virus. ${ }^{29}$ A multi-sectoral national emergency operations center (EOC) remains to manage the national COVID-19 response activities. On March 4, 2021, 709 new confirmed cases and eight deaths were put down in Nigeria. As of March 4, 2021, 157671 cases have been confirmed, 136335 cases have recovered, and 1951 deaths have been recorded in 36 states, including the Federal Capital Territory. The 709 new cases are reported from 21 states. Adamawa state displays the highest number of cases (180), while Oyo (5) and Gombe (1) states have the least number of cases across the Nation. In Nigeria, Ibadan, which is the capital of Oyo State, is one of those cities racing to return the world to normal than others; that is why the spread of COVID-19 is minimal. An average middle-aged man takes the selling of a nose mask as a job in this city to reduce the pandemic spread (Figure 2).

\section{Time}

The analysis of the disease outbreak by time was done using the epicurve (Figure 3) since the documentation about COVID-19 in Nigeria. The number of reported cases of the disease has been increasing rapidly and progressively. The outline of the epidemic curve suggests ongoing transmission of infection in the community on the 8 th week from February 22, 2021, to February 28, 2021, as shown in (Figure 3).

On February 27, 2021, Nigeria marked its one year when the COVID-19 pandemic was first reported. Nevertheless, the number of reported cases was increasing abruptly. However, in the 8 th week, the number of confirmed cases reduced to 3583 from 5720, reported in the seventh last week. ${ }^{25}$ This decrease can be traced to people's adherence to public health measures like regular washing of hands, keeping physical distance, and proper usage of nose masks. Although, on March 2, 2021, Nigeria received the first batch of COVID-19 vaccines supplied through the COVAX facility. We thought that with

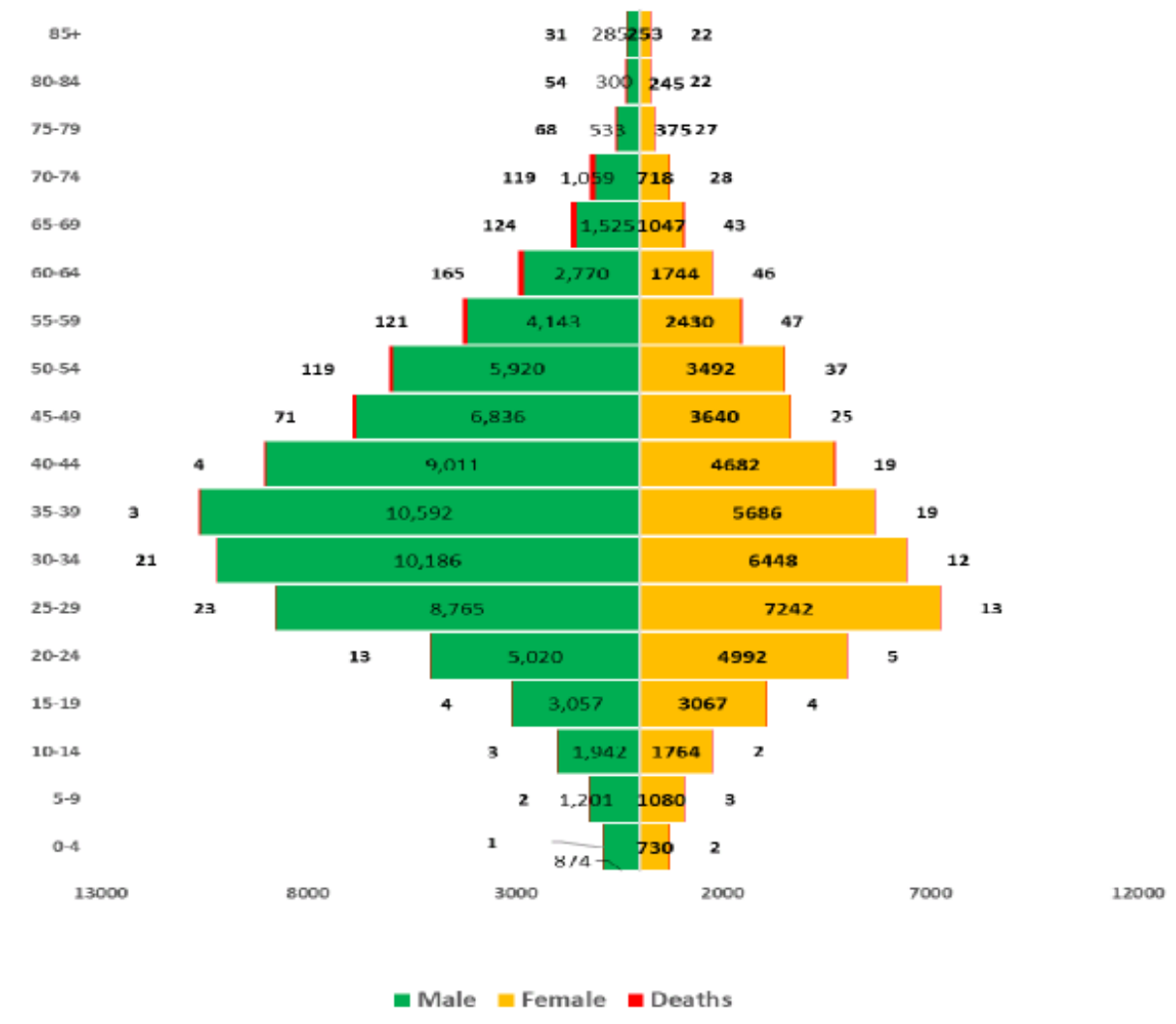

Figure 1. Sex and Age Spreading of Confirmed Cases of COVID-19 in Nigeria. ${ }^{32}$ 


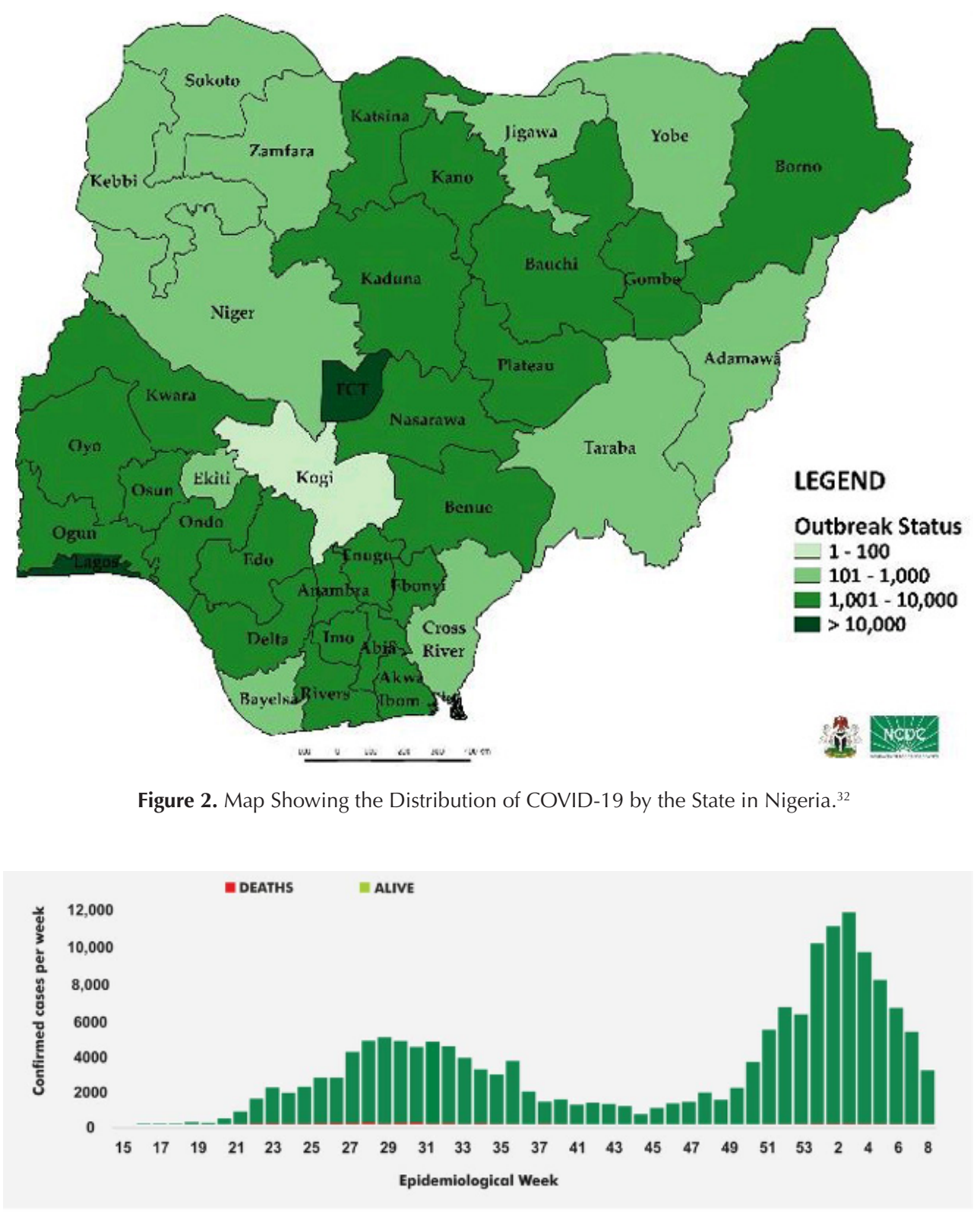

Figure 3 . The 8th-Week Prevalent Curve of Confirmed Reported Cases of COVID-19 as Reported Per Day as of February 28, 2021, in Nigeria. ${ }^{32}$

the availability of this vaccine, we would be able to record some decreases in the cases, but we see that it will take some time before the vaccine can be shared throughout the Nation. As such, we commend the effort of people for following all necessary precautions strictly to reduce COVID-19.

Also, a previous study explained the epidemiological, clinical features, results of imported and local cases outdoor Hubei Province, which suggested that imported cases were more severe than local causes, but the diagnoses could be correspondingly worthy. The little widespread period in Hainan proposes that the epidemiology of COVID-19 could be quickly brought under control if appropriate measures were put in place.

\section{Vaccinology}

Vaccinology is well-defined as studying various vaccines and generally contains immunogens, the host immune response, basic vaccine science, delivery strategies and technologies, manufacturing, and clinical evaluation. ${ }^{36}$ Additional newly, the science field has extended more to include the safety, regulatory, ethical, and economic considerations of vaccine improvement and utilization. ${ }^{36}$ Veterinary vaccines are similarly significant in the vaccinology field for their impact not solely on animal health and well-being but also on humans' food security, which is of public health importance. In 2013 , the path concerning completely synthetic vaccines by using genomic data was established. On March 31, 2013, WHO was alerted about the outbreak of a new strain of avian influenza virus, H7N9, that had infected three people in China, and 2 of these infected individuals were killed. ${ }^{37}$ It was a unique, possibly pandemic virus for which the globe was not prepared. The knowledge of the viruses like H1N1 (Spanish flu) from 1918 to 1920, H2N2 (Asian flu) from 1957 to 1958, H3N2 (Hong Kong flu) from 1968 to 1970, H1N1 (Swine flu) plague in 2009 to 2010 had revealed the vaccines had made accessible only at the ultimate of the pandemic. ${ }^{38}$ 
In Nigeria's Demographic and Health Surveys (DHS) data analysis, we found extremely high childhood non- and undervaccination rates. ${ }^{39}$ We found significant factors influencing vaccination status that various organizations can utilize, such as the Expanded Programme on Immunization (EPI). Moreover, $\mathrm{WHO}$, to raise outreach to the ethnicities, religious groups, specific regions, and socioeconomic status identified as having very low receipt of all recommended vaccines. Involvements from international aid commitments and organizations from governmental leadership to elevate service delivery tailored to regional needs and encourage vaccine delivery are essential. They need to be enacted with greater urgency than historical action to resolve the chronic stagnation in coverage. As those in the public health industry are aware, prevention is more cost-effective and offers a greater quality of life than postdiagnosis cures or treatments. ${ }^{39}$ Thus, Nigeria has the prospect to save resources and lives in the future by tactically investing in vaccine delivery in the present. This analysis also highlights the various inequalities plaguing the healthcare system in Nigeria, given the differences in ethnicity, religion, and wealth index that were revealed. As previous research has shown, associations among the number of antenatal visits, residence, and socioeconomic status with vaccination status point to the systemic issues of healthcare accessibility and distribution of resources. Addressing social issues, such as these, may be a fitting priority to alleviate the burden of low vaccination rates. However, given the exceptionally low number of children who receive all EPI recommended vaccinations in Nigeria. Even small changes related to the substantial variables of ethnicity, antenatal care, region, religion, place of delivery, and wealth index may hold the key to achieving more robust vaccination levels in Nigerian children and attaining reductions in related morbidity and mortality. ${ }^{38,39}$

When COVID-19 vaccines were available in Nigeria, respondents to COVID-19 vaccines were minimal compared to people's response to another vaccine. The spread of vaccines was very low among the masses. This increased denunciation and indefiniteness of accepting COVID-19 vaccines was mainly because of fear and misconceptions trending on the media about COVID-19 vaccines and associated health dangers.

In January 2020, when Fudan University's scientists and their coworkers posted on the internet the genomic sequence of the SARS-CoV-2, which is in charge of the current pandemic, most of the laboratories across the world were ready for the test. ${ }^{40,41}$ The genomic information of the disease has provided useful insights into the technology to make vaccines early from synthetic genes. Computer modeling of the atomic structure of the spike protein of analogous coronaviruses has been used to scheme an antigen stabilized in the prefusion conformation. ${ }^{42,43}$

Synthetic genes were quickly used to start the development of over 200 dissimilar vaccines. ${ }^{40}$ The amazing speed and excellence used for the development of the COVID-19 vaccine were possible as the scientists joined, for the first time, three eras of scientific progress in independent fields: structural vaccinology, reverse vaccinology, vaccine adjuvants, and synthetic biology. The advances in antigen selection and design (structural and reverse vaccinology) alongside the use of innovative synthetic platforms such as viral vectors, nucleic acid vaccines (RNA and DNA based). Furthermore, the availability of licensed adjuvants allowed for an unparalleled speed in discovering several COVID-19 vaccine candidates, in which many were already in the clinical development stage.

\section{COVID-19 Vaccine Development Tools}

Reverse vaccinology, synthetic biology, structural vaccinology, and vaccine adjuvants used individually to develop vaccines were combined based on a distinctive international effort to plan and develop COVID-19 vaccines (Figure 4).

\section{The Reverse Vaccinology}

The science that identifies vaccine antigens from the pathogen's genome was used for the first time in 2000 to detect new antigens for a vaccine against meningococcus $B$, which was a major problem for conventional technologies. ${ }^{44,45}$ The vaccine was licensed by the European Medicines Agency (EMA) in 2013 and by the FDA in 2015. It was shown recently to reduce about $91 \%$ of the disease incidence in Italy and $74 \%$ in the United Kingdom. ${ }^{46,47}$ In the last two decades, most vaccines have developed with genomics, exploiting the pangenome of viral and bacterial species. Significant progress in genome-based vaccines was completed in 2013 when an RNA vaccine against the H7N9 influenza virus was produced in 1 week without the virus culturing but using the genome sequence available in public databases. ${ }^{48}$ In the last few years, immunologists that deal with tumor cells used the genome of cancer cells to identify mutations coding for neoantigens to be combined in cancer vaccines. ${ }^{49}$

\section{The Structural Vaccinology}

Structural vaccinology (design based on structure antigen) was foreseen as an evolving field in 2007 when it became clear that high-throughput structure determination would be possible in the nearest future. ${ }^{50}$ Nevertheless, it had previously been anticipated in 2002 that the study of antibodies recognizing protective epitopes would inform vaccine design. ${ }^{51}$ The first example published in 2011 was the design of a single meningococcal antigen that contained the epitopes of three antigenic variants of a similar molecule. ${ }^{52}$ In 2013, structurebased vaccine design was used for the first time to develop a vaccine that had been difficult for other technologies, when McLellan et al, ${ }^{53,54}$ described the stabilization of the respiratory syncytial virus fusion protein in the prefusion conformation. In 2019, the prefusion stabilized Fusion protein was shown to induce unprecedented neutralizing antibody levels and ready for phase III clinical trials. ${ }^{55}$ In 2013, a structure-based design was also used for germline immunization to make broadly neutralizing antibodies against the Human immunodeficiency virus (HIV).${ }^{56}$ Lastly, in 2015, structural vaccinology was used to modify the spike protein of the Middle East respiratory syndrome-related coronavirus (MERS-CoV) in the prefusion conformation. $^{40}$ In 2017, a perspective in the Journal of Experimental Medicine foretold the merging of reverse and 


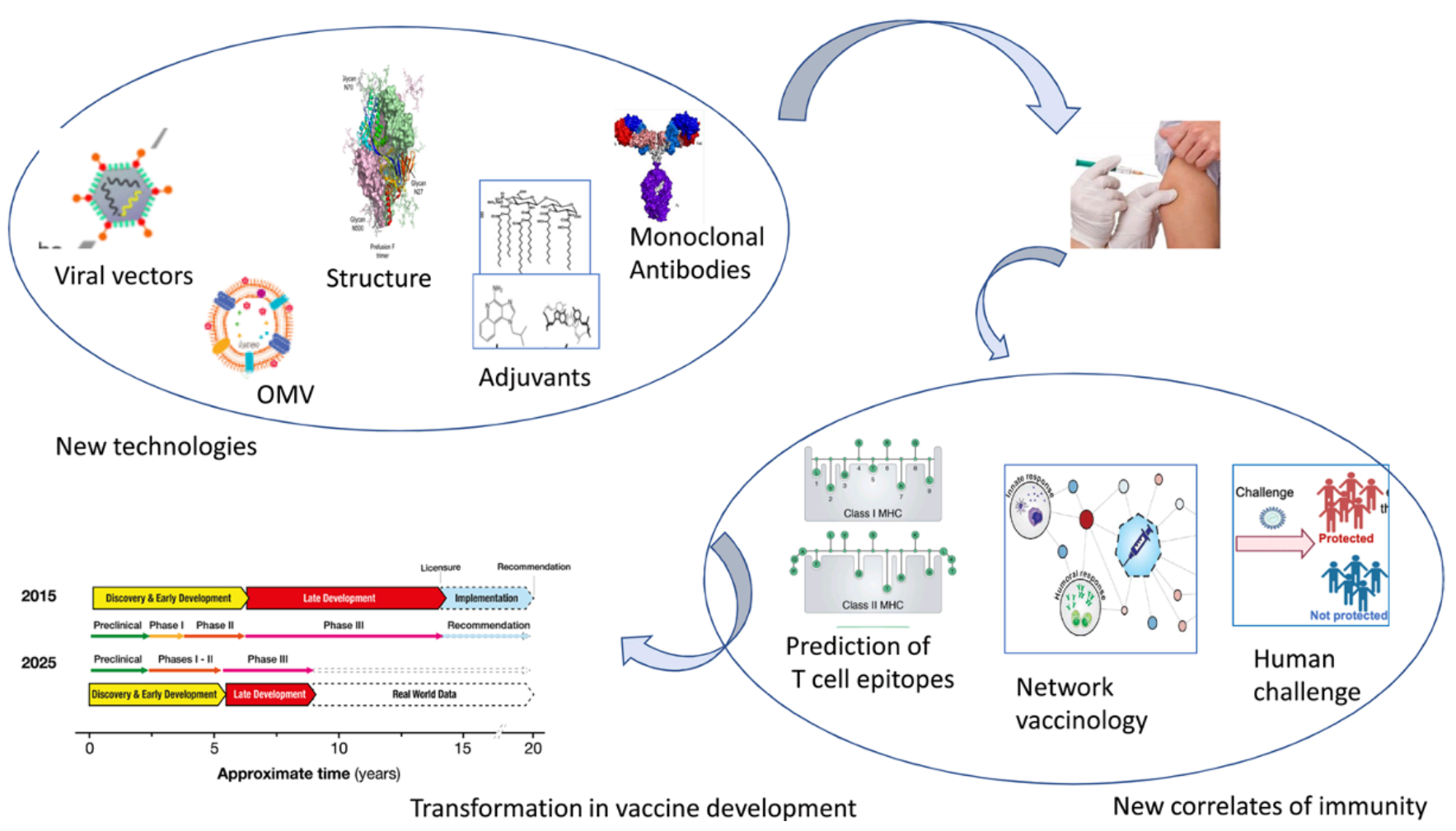

Figure 4. New Tools and New Correlates of Immunity Instruct the Transformation in Vaccine Development. ${ }^{35}$

structural vaccinology and named it reverse vaccinology $2.0 .^{57}$

\section{The Synthetic Biology}

There is the ability to use synthetic genes for vaccination as well as cancer therapy. It was initiated in 1986 by using a cloned gene into a viral vector for gene therapy, ${ }^{58}$ and, in 1992, by replicating the glycoprotein gene of rabies virus into a canarypox viral vector for the development of rabies vaccine. ${ }^{59}$ Separately, it was shown that protein expression could be achieved by the direct transfer of genes into mouse muscle cells. ${ }^{60}$ This observation recommended the usage of naked DNA, ${ }^{61,62}$ and $\mathrm{RNA}^{63}$ for vaccination. DNA vaccination became very prevalent during the subsequent decade until it was discovered that, while successful in most animal models, it has not been, until recently, successful in humans. ${ }^{40}$ The degeneration of DNA popularity led to the rekindling of viral vectors and RNA at the end of the first decade of the 21 st century. In this period, viral vectors became widespread. They were widely used for the rapid generation of vaccines to fight the Ebola epidemic in 2014, which led to the permission of the first viral vector vaccine produced in 2019. So far, there have been technological advancements to produce, stabilize, and deliver RNA in the pharmaceutical industry to develop antisense RNA therapeutics. The technology that permitted RNA delivery using lipid nanoparticles was transferred to vaccines and allowed the efficient delivery of RNA vaccines, ${ }^{64}$ and the rapid development of fully synthetic RNA vaccines in 1 week against an emerging pathogen. ${ }^{3,47}$ In the last few years, the production and clinical testing of RNA vaccines and viral vectors have increased exponentially. These technologies are currently being used to produce vaccines to tackle the SARSCoV-2 pandemic.

\section{Vaccine Adjuvants}

Vaccine adjuvants are substances that are added to vaccines to alleviate their potency. Aluminum hydroxide, along with aluminum phosphate, has been used since the 1920s..$^{38,39}$ MF59 (Novartis International AG, Basal, Switzerland), the first modern adjuvant in 1997, was licensed to recover an influenza vaccine. ${ }^{65}$ Ever since then, numerous novel adjuvants have been licensed and used by many people. The other adjuvants licensed today are AS01, AS03, AS04, and $\mathrm{CpG}$ oligonucleotides used for herpes zoster, pandemic influenza, papillomavirus, and hepatitis B. ${ }^{66}$ The clinical assessment setting, MF59, alum, CpG, AS03, and Matrix-M are being used for COVID-19 vaccines.

In January 2020, these four tools, as stated above, were used together to develop some COVID-19 vaccines. ${ }^{40} \mathrm{~A}$ SARS-CoV-2 nucleotide sequence coding for the spike protein was derived from the genome sequence uploaded on public databases (reverse vaccinology). The synthetic gene was modified to introduce the earlier mutations to stabilize the coronavirus antigen in the prefusion form (structural vaccinology) and used for RNA and viral vector vaccines (synthetic biology). The protein-based vaccines (as viral-like particles, stabilized recombinant trimers, and nanoparticles) were combined with adjuvants. However, some SARS$\mathrm{CoV}-2$ vaccines in the clinic use other approaches such as attenuation or inactivation of the virus; the combination of these tools and the coordinated global effort allowed for an unparalleled speed in discovering numerous COVID-19 vaccine candidates.

Vaccines for COVID-19

Some approaches are used to make COVID-19 vaccines and 
nucleic acid-based vectors, inactivated or live attenuated viruses, recombinant proteins, and virus-like particles. ${ }^{41}$ In this write-up, we focused mainly on three categories of vaccines demonstrating immense developmental acceleration: synthetic RNA vaccines, viral vectors, and adjuvant proteinbased vaccines (Figure 5).

Synthetic RNA vaccines are the fastest to develop. A completely synthetic gene is cloned in a plasmid vector, which is then used as a template for the in vitro synthesis of the RNA vaccine.$^{6}$ RNA vaccines are divided into two types: those that encode an antigen and those that encode an antigen along with the enzymatic machinery for RNA template replication following vaccination (self-amplifying $\mathrm{RNA}^{27,34}$ ). The study of Jackson's in 2020 showed RNA vaccines that were completely synthetic and do not need a biological phase were able to get to clinical trials in 66 days (record time) and moved from phase I to phase II clinical trials in below five months. ${ }^{69}$ Immunogenicity, and efficacy data in humans were produced in 10 months..$^{70,71}$ Currently, RNA vaccines are among the most promising vaccine tools. They could be one of the most vital platforms of the future. However, we need to be informed that, at present, we do not have a licensed RNA vaccine so far. Thus, this type of vaccine still needs to experience the challenges of demonstrating safety, immunogenicity, and its efficacy in a large human population. Additionally, the manufacturing of RNA vaccines, even though being much simpler than conventional vaccines, has never been pushed up beyond the need for clinical trials. The urgency to combat COVID-19 and to prevent infectious diseases similar to SARS CoV-2 provides an unprecedented opportunity to accelerate this tool and quicken its maturation.

In viral vectors, the synthetic gene coding for spike protein is inserted into one of many viruses modified to prevent the reproduction of the disease in the human host. The virus is then cultivated in culture and used to transport the synthetic gene during vaccination. Many viruses can be used to perform this purpose. The most common ones are adenoviruses (Chimpanzee adenovirus, human adenoviruses 5 and 26), modified vaccinia Ankara, measles virus, cytomegalovirus, and vesicular stomatitis virus (VSV). ${ }^{72,73}$ The only licensed vaccine based on viral vectors is the Ebola vaccines based on human adenovirus 26 and VSV..$^{39}$ Though we have a long experience of clinical trials with viral vector vaccines, these vaccines have not been used in millions of people. Hence, the need to move forward carefully with this method. Extensive manufacturing capacity to produce hundreds of millions of doses does not yet exist in the industry. It is being fasttracked with extraordinary public and private investments to accelerate COVID-19 vaccines. It is also vital to call attention to vector immunity which has remained a concern with viral and bacterial vectors. Boosting vaccines with the same vector has restrictions, and this could influence using the same vector for a dissimilar pathogen, an issue that should be carefully considered.

Protein-based vaccines are the only ones for which we have a great experience. In this case, the synthetic gene coding for the spike protein, prefusion stabilized or receptor-binding domain only, is used to engineer mammalian cells, baculovirus, or plant cells to produce the purified recombinant protein, joined with adjuvants, and used as a vaccine. The primary phase of these vaccines involves the cell line's generation, and the protein's purification requires more time than RNA or viral vector vaccines. Hence, at least six months were needed before the first protein-based COVID-19 vaccine started clinical trials. ${ }^{74}$ Initial data on immunogenicity in humans shows that these vaccines induce very high neutralizing titers that surpass those found in recovering patients due to vaccination.

\section{Conclusion}

The COVID-19 pandemic appears to be escalating with several unknown factors. Hopefully, in the future, as the epidemic progresses and vaccines become widely available, the true burden of this infectious agent will be reduced. Based on the spread of this disease worldwide, it is evident that there is a crucial need for COVID-19 vaccines or alternative therapies to battle this agent. Until an adequate quantity of COVID-19 vaccine is supplied throughout the world, social distancing is advised to prevent the spread of this disease. The use of monoclonal antibodies is recommended for treatment if available.

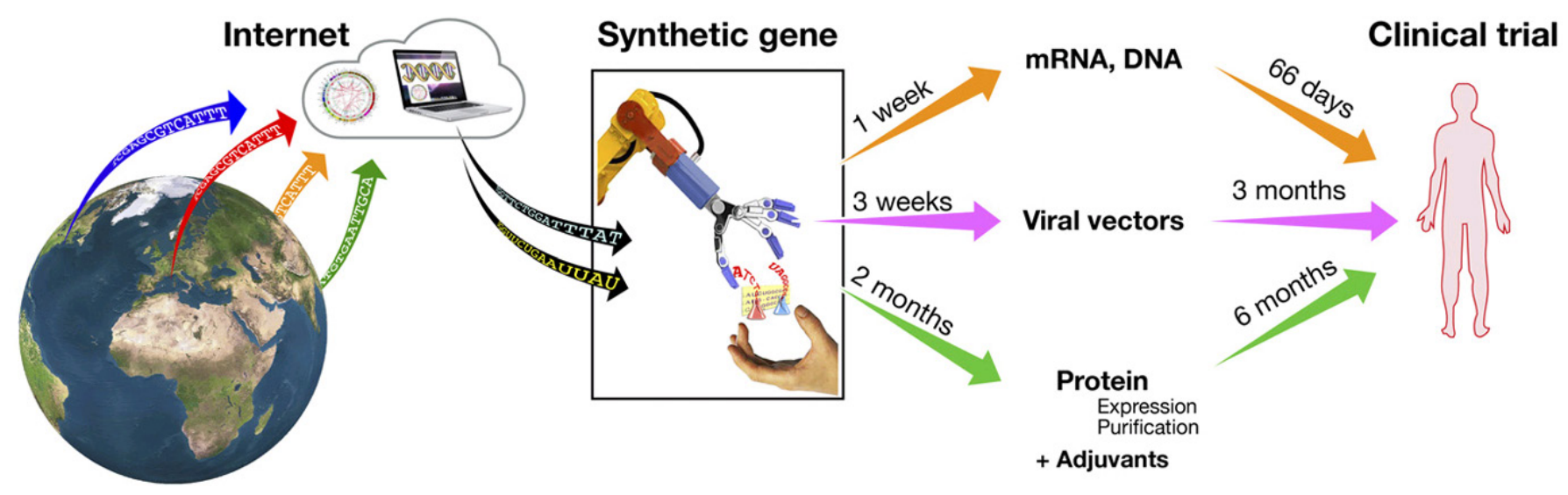

Figure 5. COVID-19 Vaccines in Development and Their Timeline to Clinical Testing in Humans. ${ }^{67}$ 


\section{Review Highlights}

What Is Already Known?

Coronavirus family has two strains, namely the SARSCoV-2 and the MERS-CoV for earlier outbreaks. In 2002 and 2003, SARS-CoV caused a global outbreak that began in Guangdong Province, China. Another novel COVID-19 was confirmed as the global pandemic on March 11, 2020, by the WHO, was caused by the outbreak of an emergent SARS-CoV-2, which was first reported in Wuhan city, China, in December 2019. The disease affected over 8000 people and caused severe pulmonary diseases in several countries. Nigeria had its first COVID-19 on February 27, 2020, introduced by a visiting Italian. The vaccine, which it studies referred to as vaccinology. Vaccinology generally contains the study vaccine, immunogens, the host immune response, basic vaccine science, delivery strategies and technologies, manufacturing, and clinical evaluation. This field has extended more to include the safety, regulatory, ethical, and economic considerations of vaccine improvement and utilization.

\section{What Does This Study Add?}

The epidemiology of COVID-19 cases in Nigeria has been recently described majorly in three different entities: the place, person, and time. The place described the spread of COVID-19 with the states in Nigeria, the person described the spread within age groups, and the time described the weekly spread from February 28, 2021. For the amazing speed and excellent development of the COVID-19 vaccine, the scientists used three eras of scientific progress in independent fields: structural vaccinology, reverse vaccinology, vaccine adjuvants, and synthetic biology.

\section{Authors' Contributions}

All authors contributed equally to the current study.

\section{Conflict of Interests}

The authors declare that they have no conflicts of interest.

\section{Ethics Approval}

Not applicable.

\section{Funding/Support}

None.

\section{Acknowledgments}

The authors would like to express their gratitude to Mr. Abolaji Samson Olagunju, a post-graduate student at the Department of Biochemistry, University of Ibadan (UI), Ibadan, Nigeria, and Dr. Omirinde Jamiu, Faculty of Veterinary Medicine, University of Jos, Nigeria, for their support in the preparation of this manuscript.

\section{References}

1. Tyrrell DA, Almeida JD, Cunningham CH, et al. Coronaviridae. Intervirology. 1975;5(1-2):76-82. doi:10.1159/000149883.

2. Yin $Y$, Wunderink RG. MERS, SARS and other coronaviruses as causes of pneumonia. Respirology. 2018;23(2):130-137. doi:10.1111/resp.13196.
3. World Health Organization. SARS (Severe Acute Respiratory Syndrome) Geneva. 2020. https://www.who.int/ith/diseases/ sars/en/. Accessed March 14, 2021.

4. Updated information on the epidemiology of Middle East respiratory syndrome coronavirus (MERS-CoV) infection and guidance for the public, clinicians, and public health authorities, 2012-2013. MMWR Morb Mortal Wkly Rep. 2013;62(38):793796.

5. Zhu N, Zhang D, Wang W, et al. A novel coronavirus from patients with pneumonia in China, 2019. N Engl J Med. 2020;382(8):727-733. doi:10.1056/NEJMoa2001017.

6. Banerjee A, Doxey AC, Mossman K, Irving AT. Unraveling the zoonotic origin and transmission of SARS-CoV-2. Trends Ecol Evol. 2021;36(3):180-184. doi:10.1016/j.tree.2020.12.002.

7. Chan JF, Yuan S, Kok KH, et al. A familial cluster of pneumonia associated with the 2019 novel coronavirus indicating personto-person transmission: a study of a family cluster. Lancet. 2020;395(10223):514-523. doi:10.1016/s0140-6736(20)301549.

8. Lu R, Zhao X, Li J, et al. Genomic characterisation and epidemiology of 2019 novel coronavirus: implications for virus origins and receptor binding. Lancet. 2020;395(10224):565574. doi:10.1016/s0140-6736(20)30251-8.

9. Zhou P, Yang XL, Wang XG, et al. A pneumonia outbreak associated with a new coronavirus of probable bat origin. Nature. 2020;579(7798):270-273. doi:10.1038/s41586-0202012-7.

10. World Health Organization. WHO Director- General's opening remarks at the media briefing on COVID-19. 2020. https:// www.who.int/dg/speeches/detail/who-director-general-sopening-remarks-at the- media-briefing on-covid-19---11April- 2020. Accessed February 11, 2020.

11. World Health Organization. Novel Coronavirus (2019-nCoV) Situation Report. https://www.who.int/emergencies/diseases/ novel-coronavirus-2019/situation-reports. Accessed 4th March 2021.

12. Ong SWX, Tan YK, Chia PY, et al. Air, surface environmental, and personal protective equipment contamination by severe acute respiratory syndrome coronavirus 2 (SARS-CoV-2) from a symptomatic patient. JAMA. 2020;323(16):1610-1612. doi:10.1001/jama.2020.3227.

13. Yang Y, Lu QB, Liu MJ, et al. Epidemiological and clinical features of the 2019 novel coronavirus outbreak in China. medRxiv. 2020. doi:10.1101/2020.02.10.20021675.

14. Phan LT, Nguyen TV, Luong QC, et al. Importation and humanto-human transmission of a novel coronavirus in Vietnam. N Engl J Med. 2020;382(9):872-874. doi:10.1056/NEJMc2001272.

15. Adekunle AI, Adegboye OA, Gayawan E, McBryde ES. Is Nigeria really on top of COVID-19? message from effective reproduction number. Epidemiol Infect. 2020;148:e166. doi:10.1017/s0950268820001740.

16. Zhang SY, Zhang Q, Casanova JL, Su HC. Severe COVID-19 in the young and healthy: monogenic inborn errors of immunity? Nat Rev Immunol. 2020;20(8):455-456. doi:10.1038/s41577020-0373-7.

17. Chen N, Zhou M, Dong X, et al. Epidemiological and clinical characteristics of 99 cases of 2019 novel coronavirus pneumonia in Wuhan, China: a descriptive study. Lancet. 2020;395(10223):507-513. doi:10.1016/s0140-6736(20)302117.

18. Zimmermann P, Curtis N. COVID-19 in children, pregnancy and neonates: a review of epidemiologic and clinical features. 
Pediatr Infect Dis J. 2020;39(6):469-477. doi:10.1097/ inf.0000000000002700.

19. Ludvigsson JF. Systematic review of COVID-19 in children shows milder cases and a better prognosis than adults. Acta Paediatr. 2020;109(6):1088-1095. doi:10.1111/apa.15270.

20. Huang C, Wang Y, Li X, et al. Clinical features of patients infected with 2019 novel coronavirus in Wuhan, China. Lancet. 2020;395(10223):497-506. doi:10.1016/s0140-6736(20)301835.

21. Bukhari Q, Massaro JM, D’Agostino RB Sr, Khan S. Effects of weather on coronavirus pandemic. Int J Environ Res Public Health. 2020;17(15):5399. doi:10.3390/ijerph17155399.

22. Brassey J, Heneghan C, Mahtani KR, Aronson JK. Do weather conditions influence the transmission of the coronavirus (SARS-CoV-2)? Centre for Evidence-Based Medicine; 2020

23. Ujiie M, Tsuzuki S, Ohmagari N. Effect of temperature on the infectivity of COVID-19. Int J Infect Dis. 2020;95:301-303. doi:10.1016/j.ijid.2020.04.068.

24. Shi P, Dong $\mathrm{Y}$, Yan $\mathrm{H}$, et al. Impact of temperature on the dynamics of the COVID-19 outbreak in China. Sci Total Environ. 2020;728:138890. doi:10.1016/j.scitotenv.2020.138890.

25. Heneghan C, Jefferson T. Effect of latitude on COVID-19. Centre for Evidence-Based Medicine; 2020.

26. John Hopkins University. COVID-19 dashboard by center for systems science and engineering at the John Hopkins University. https://Coronavirus.jhu.edu/map.html.

27. Nkengasong JN, Mankoula W. Looming threat of COVID-19 infection in Africa: act collectively, and fast. Lancet. 2020;395(10227):841-842. doi:10.1016/s0140-6736(20)304645.

28. World Health Organization. COVID-19 in the African Region: WHO Africa Dashboard. https://www.afro.who.int/ healthtopics/Coronavirus-covid-19.

29. Nigeria Centre for Disease Control. COVID-19 in Nigeria. https://covid19.ncdc.gov.ng/.

30. [The epidemiological characteristics of an outbreak of 2019 novel coronavirus diseases (COVID-19) in China]. Zhonghua Liu Xing Bing Xue Za Zhi. 2020;41(2):145-151. doi:10.3760/cm a.j.issn.0254-6450.2020.02.003.

31. Bob Curley. Why COVID-19 is hitting Men Harder than Women. 2020. https://www.healthline.com/health-news/menmore-susceptible-to-serious-covid-19-illnesses. Accessed April $14,2021$.

32. NCDC COVID-19 Situation Report 2021. http://covid19.ncdc. gov.ng/.

33. Zhou F, Yu T, Du R, et al. Clinical course and risk factors for mortality of adult inpatients with COVID-19 in Wuhan, China: a retrospective cohort study. Lancet. 2020;395(10229):10541062. doi:10.1016/s0140-6736(20)30566-3.

34. Wang D, Yin Y, Hu C, et al. Clinical course and outcome of 107 patients infected with the novel coronavirus, SARS-CoV-2, discharged from two hospitals in Wuhan, China. Crit Care. 2020;24(1):188. doi:10.1186/s13054-020-02895-6.

35. Dan-Nwafor C, Ochu CL, Elimian K, et al. Nigeria's public health response to the COVID-19 pandemic: January to May 2020. J Glob Health. 2020;10(2):020399. doi:10.7189/jogh.10.020399.

36. Barrett ADT. Vaccinology in the twenty-first century. NPJ Vaccines. 2016;1:16009. doi:10.1038/npjvaccines.2016.9.

37. Gao R, Cao B, Hu Y, et al. Human infection with a novel avian-origin influenza A (H7N9) virus. $N$ Engl J Med. 2013;368(20):1888-1897. doi:10.1056/NEJMoa1304459.

38. Saunders-Hastings PR, Krewski D. Reviewing the history of pandemic influenza: understanding patterns of emergence and transmission. Pathogens. 2016;5(4):66. doi:10.3390/ pathogens5040066.

39. McGavin ZA, Wagner AL, Carlson BF, Power LE, Eboreime E, Boulton ML. Childhood full and under-vaccination in Nigeria, 2013. Vaccine. 2018;36(48):7294-7299. doi:10.1016/j. vaccine.2018.10.043.

40. Rappuoli R, De Gregorio E, Del Giudice G, et al. Vaccinology in the post-COVID-19 era. Proc Natl Acad Sci U S A. 2021;118(3):e2020368118. doi:10.1073/pnas.2020368118.

41. Podda A. The adjuvanted influenza vaccines with novel adjuvants: experience with the MF59-adjuvanted vaccine. Vaccine. 2001;19(17-19):2673-2680. doi:10.1016/s0264410x(00)00499-0.

42. Pallesen J, Wang N, Corbett KS, et al. Immunogenicity and structures of a rationally designed prefusion MERS-CoV spike antigen. Proc Natl Acad Sci U S A. 2017;114(35):E7348-E7357. doi:10.1073/pnas.1707304114.

43. Wrapp D, Wang N, Corbett KS, et al. Cryo-EM structure of the 2019-nCoV spike in the prefusion conformation. Science. 2020;367(6483):1260-1263. doi:10.1126/science.abb2507.

44. Pizza M, Scarlato V, Masignani V, et al. Identification of vaccine candidates against serogroup B meningococcus by wholegenome sequencing. Science. 2000;287(5459):1816-1820. doi:10.1126/science.287.5459.1816.

45. Rappuoli R. Reverse vaccinology. Curr Opin Microbiol. 2000;3(5):445-450. doi:10.1016/s1369-5274(00)00119-3.

46. Ladhani SN, Andrews N, Parikh SR, et al. Vaccination of infants with meningococcal group $\mathrm{B}$ vaccine $(4 \mathrm{CMenB})$ in England. N Engl J Med. 2020;382(4):309-317. doi:10.1056/ NEJMoa1901229.

47. Azzari C, Moriondo M, Nieddu F, et al. Effectiveness and impact of the $4 \mathrm{CMenB}$ vaccine against group $\mathrm{B}$ meningococcal disease in two Italian regions using different vaccination schedules: a five-year retrospective observational study (2014-2018). Vaccines (Basel). 2020;8(3):469. doi:10.3390/vaccines8030469.

48. Hekele A, Bertholet S, Archer J, et al. Rapidly produced SAM( $\left.{ }^{\circ}\right)$ vaccine against $\mathrm{H} 7 \mathrm{~N} 9$ influenza is immunogenic in mice. Emerg Microbes Infect. 2013;2(8):e52. doi:10.1038/emi.2013.54.

49. Schumacher TN, Schreiber RD. Neoantigens in cancer immunotherapy. Science. 2015;348(6230):69-74. doi:10.1126/ science.aaa4971.

50. Serruto D, Rappuoli R. Post-genomic vaccine development. FEBS Lett. 2006;580(12):2985-2992. doi:10.1016/j. febslet.2006.04.084.

51. Burton DR. Antibodies, viruses and vaccines. Nat Rev Immunol. 2002;2(9):706-713. doi:10.1038/nri891.

52. Scarselli M, Aricò B, Brunelli B, et al. Rational design of a meningococcal antigen inducing broad protective immunity. Sci Transl Med. 2011;3(91):91ra62. doi:10.1126/ scitranslmed.3002234.

53. McLellan JS, Chen M, Leung S, et al. Structure of RSV fusion glycoprotein trimer bound to a prefusion-specific neutralizing antibody. Science. 2013;340(6136):1113-1117. doi:10.1126/ science.1234914.

54. McLellan JS, Chen M, Joyce MG, et al. Structure-based design of a fusion glycoprotein vaccine for respiratory syncytial virus. Science. 2013;342(6158):592-598. doi:10.1126/science.1243283.

55. Crank MC, Ruckwardt TJ, Chen M, et al. A proof of concept for structure-based vaccine design targeting RSV in humans. Science. 2019;365(6452):505-509. doi:10.1126/science.aav9033. 56. Jardine J, Julien JP, Menis S, et al. Rational HIV immunogen 
design to target specific germline B cell receptors. Science. 2013;340(6133):711-716. doi:10.1126/science. 1234150.

57. Rappuoli R, Bottomley MJ, D’Oro U, Finco O, De Gregorio E. Reverse vaccinology 2.0: human immunology instructs vaccine antigen design. J Exp Med. 2016;213(4):469-481. doi:10.1084/ jem. 20151960 .

58. Gilboa E, Eglitis MA, Kantoff PW, Anderson WF. Transfer and expression of cloned genes using retrovial vectors. Biotechniques. 1986;4(6):504-512.

59. Cadoz M, Strady A, Meignier B, et al. Immunisation with canarypox virus expressing rabies glycoprotein. Lancet. 1992;339(8807):1429-1432. doi:10.1016/01406736(92)92027-d.

60. Wolff JA, Malone RW, Williams P, et al. Direct gene transfer into mouse muscle in vivo. Science. 1990;247(4949 Pt 1):1465-1468. doi:10.1126/science.1690918.

61. Tang DC, DeVit M, Johnston SA. Genetic immunization is a simple method for eliciting an immune response. Nature. 1992;356(6365):152-154. doi:10.1038/356152a0.

62. Ulmer JB, Donnelly JJ, Parker SE, et al. Heterologous protection against influenza by injection of DNA encoding a viral protein. Science. 1993;259(5102):1745-1749. doi:10.1126/ science. 8456302 .

63. Martinon F, Krishnan S, Lenzen G, et al. Induction of virusspecific cytotoxic T lymphocytes in vivo by liposome-entrapped mRNA. Eur J Immunol. 1993;23(7):1719-1722. doi:10.1002/ eji. 1830230749 .

64. Geall AJ, Verma A, Otten GR, et al. Nonviral delivery of self-amplifying RNA vaccines. Proc Natl Acad Sci U S A. 2012;109(36):14604-14609. doi:10.1073/pnas.1209367109.

65. HogenEsch H, O'Hagan DT, Fox CB. Optimizing the utilization of aluminum adjuvants in vaccines: you might just get what you want. NPJ Vaccines. 2018;3:51. doi:10.1038/s41541-018- 0089-x.

66. Del Giudice G, Rappuoli R, Didierlaurent AM. Correlates of adjuvanticity: a review on adjuvants in licensed vaccines. Semin Immunol. 2018;39:14-21. doi:10.1016/j.smim.2018.05.001.

67. Krammer F. SARS-CoV-2 vaccines in development. Nature. 2020;586(7830):516-527. doi:10.1038/s41586-020-2798-3.

68. Maruggi G, Zhang C, Li J, Ulmer JB, Yu D. mRNA as a transformative technology for vaccine development to control infectious diseases. Mol Ther. 2019;27(4):757-772. doi:10.1016/j.ymthe.2019.01.020.

69. Jackson LA, Anderson EJ, Rouphael NG, et al. An mRNA vaccine against SARS-CoV-2 - preliminary report. N Engl J Med. 2020;383(20):1920-1931. doi:10.1056/NEJMoa2022483.

70. Sahin U, Muik A, Derhovanessian E, et al. COVID-19 vaccine BNT162b1 elicits human antibody and $\mathrm{T}(\mathrm{H}) 1 \mathrm{~T}$ cell responses. Nature. 2020;586(7830):594-599. doi:10.1038/s41586-0202814-7.

71. Anderson EJ, Rouphael NG, Widge AT, et al. Safety and immunogenicity of SARS-CoV-2 mRNA-1273 vaccine in older adults. N Engl J Med. 2020;383(25):2427-2438. doi:10.1056/ NEJMoa2028436.

72. Bloom DE, Black S, Rappuoli R. Emerging infectious diseases: a proactive approach. Proc Natl Acad Sci U S A. 2017;114(16):4055-4059. doi:10.1073/pnas.1701410114.

73. Folegatti PM, Ewer KJ, Aley PK, et al. Safety and immunogenicity of the ChAdOx1 nCoV-19 vaccine against SARS-CoV-2: a preliminary report of a phase $1 / 2$, single-blind, randomised controlled trial. Lancet. 2020;396(10249):467-478. doi:10.1016/ s0140-6736(20)31604-4.

74. Keech C, Glenn GM, Albert G, et al. First-in-human trial of a SARS-CoV-2 recombinant spike protein nanoparticle vaccine. medRxiv. 2020. doi:10.1101/2020.08.05.20168435. 